\title{
Association of inflammation and endothelial dysfunction with metabolic syndrome, prediabetes and diabetes in adults from Inner Mongolia, China
}

Angela M Thompson ${ }^{1}$, Yonghong Zhang ${ }^{2}$, Weijun Tong ${ }^{2}$, Tan X ${ }^{2}$, Jing Chen ${ }^{1,3}$, Li Zhao ${ }^{4}$, Tanika N Kelly ${ }^{1}$, Chung-Shiuan Chen', Lydia A Bazzano ${ }^{1,3}$ and Jiang $\mathrm{He}^{1,3^{*}}$

\begin{abstract}
Background: We examined the association of biomarkers of inflammation and endothelial dysfunction with diabetes and metabolic syndrome (MetS) in persons from Inner Mongolia.

Methods: A cross-sectional study was conducted among 2,536 people aged 20 years and older from Inner Mongolia, China. Overnight fasting blood samples were obtained to measure plasma concentrations of high sensitivity C-reactive protein (hsCRP), soluble inter-cellular adhesion molecule-1 (sICAM-1), sE-selectin, angiotensin II, high density lipoprotein cholesterol, triglycerides, and blood glucose. Waist circumference and blood pressure were measured by trained staff. MetS was defined according to the modified ATP III definition for Asians. Elevated level of the biomarker was defined as values in the upper tertile of the distribution. Participants were categorized into one of four groups based on the presence or absence of metabolic and glycemic abnormalities: 1) free of prediabetes, diabetes and MetS (reference group), 2) prediabetes or diabetes only, 3) MetS without prediabetes or diabetes, and 4) MetS plus prediabetes or diabetes. The multivariable models are adjusted for age, gender, smoking, drinking, family history of hypertension, and body mass index.
\end{abstract}

Results: Among study participants, $18.5 \%$ had prediabetes, 3.6\% had diabetes, and $27.4 \%$ of the entire study population had 3 or more components of the MetS. Elevated hsCRP was associated with an increased odds of prediabetes or diabetes only, MetS without prediabetes or diabetes, and MetS plus prediabetes or diabetes with multivariable adjusted odds ratios (95\% confidence intervals) of 2.3 (1.7-3.1), 3.0 (2.4-3.8), and 5.8 (4.5-7.5), respectively. Elevated sICAM-1 was associated with increased odds $(95 \% \mathrm{Cl})$ of prediabetes or diabetes only (2.1, 1.6-2.9) and MetS plus prediabetes or diabetes (4.2, 3.2-5.3) but was not associated with MetS alone. Elevated sEselectin was associated with a modestly increased risk of MetS (OR 1.7, 95\% Cl 1.4-2.2). Elevated levels of Angiotensin II were not associated with the MetS plus prediabetes or diabetes in this study.

Conclusions: Diabetes and the MetS are common in the Inner Mongolia population. The biomarkers of inflammation and endothelial dysfunction are associated with increased risk for diabetes and MetS in this population. These results are consistent with results from other populations.

Keywords: metabolic syndrome, diabetes, inflammation, endothelial dysfunction, C-reactive protein, intercellular adhesion molecule-1, E-selectin

\footnotetext{
* Correspondence: jhe@tulane.edu

'Department of Epidemiology, Tulane University School of Public Health and

Tropical Medicine, New Orleans, Louisiana, USA

Full list of author information is available at the end of the article
} 


\section{Background}

The metabolic syndrome (MetS) is common in the United States and has become more prevalent worldwide in recent years. While much has been written about the MetS in US and European populations, less is known about the epidemiology of MetS in non-western countries [1-3]. In a nationally representative sample of adults in China, the age-standardized prevalence of MetS was reported to be higher in women (29.1\%) than men (17.7\%), in northern (30.9\%) compared to southern (18.2\%) China, and in urban areas (31.0\%) compared to rural $(21.6 \%)$ areas [4]. It is estimated that $66 \%$ of persons with diabetes also have the MetS [5]. In Chinese adults, the age-standardized prevalence of prediabetes, diabetes and MetS were reported to be $15.5 \%, 9.7 \%$, and $23.3 \%$, respectively $[4,6]$.

MetS is characterized by the presence of multiple cardiovascular risk factors including abdominal obesity, dyslipidemia, elevated glucose and elevated blood pressure [7]. The risk of cardiovascular disease (CVD) morbidity and mortality is elevated among those with MetS [8-10], and as the number of metabolic abnormalities increase, the risks of stroke, [11], chronic kidney disease [12] and CVD [13,14] increase. However, not all of the components of MetS confer the same amount of risk. In Western populations, elevated blood glucose may be the primary force driving the development of MetS and subsequent CVD risk [8]. Diabetes confers a high risk for CVD mortality that is modified little by the addition of the other MetS risk factors [15].

Biomarkers of inflammation and endothelial dysfunction have been associated with diabetes [16-19] and the MetS [20-22]. They may explain as much as $43 \%$ of the excess risk for CVD mortality among persons with diabetes [16] and up to $26 \%$ of the association between MetS and coronary artery disease [23]. However, the associations reported have been inconsistent in Western and Asian populations [16,20,24-30]. To our knowledge, no previous study has examined this association in persons of Mongolian ethnicity. In the current study, we examined the association between biomarkers of inflammation and endothelial dysfunction with categories of metabolic or glycemic abnormality in a lean, farming population from Inner Mongolia, China.

\section{Methods \\ Subjects}

A cross-sectional study was conducted between 2002 and 2003 in Inner Mongolia, an autonomous region in north China. The methods for selection of study participants and data collection have been described elsewhere [31]. Briefly, individuals aged 20 years and older were recruited from 32 villages in two adjacent townships located in Kezuohou Banner and Naiman Banner in Inner Mongolia. The majority of local residents were Mongolians who had lived there for many generations, their professions were farmers and herdsmen and they maintained a traditional diet that was high in fat and salt. Out of 3,475 eligible people, a total of 2,589 individuals chose to participate. Those who did not have a measurement for one or more of the components for MetS were excluded $(n=53)$ and a total of 2,536 persons were included in this analysis. Written informed consent was obtained for all study participants. This study was approved by the ethics committee at Soochow University in China and institutional review board at Tulane University Health Sciences Center in the United States.

\section{Data Collection}

Trained staff interviewed participants in Chinese using a standard questionnaire to obtain information on demographic characteristics, medical history, and lifestyle risk factors such as cigarette smoking and alcohol consumption. Three sitting blood pressure measurements were taken for each participant using a mercury sphygmomanometer according to a standard protocol. The mean of these three blood pressure measurements was used in the data analysis. Height and body weight were measured by trained staff using a balance beam scale after subjects removed their shoes and were wearing light clothing. Body mass index (BMI) was calculated as weight in kilograms divided by the square of the height in meters $\left(\mathrm{kg} / \mathrm{m}^{2}\right)$. Waist circumference was measured at the level of $1 \mathrm{~cm}$ above the umbilicus.

Overnight fasting blood samples were obtained to measure cholesterol, blood glucose, insulin, high sensitivity C-reactive protein (hsCRP), soluble intercellular adhesion molecule-1 (sICAM-1), soluble E-selectin (sEselectin) and angiotensin II. Plasma and serum samples were frozen at $-80^{\circ} \mathrm{C}$ until laboratory testing. Concentrations of total cholesterol, high density lipoprotein (HDL) cholesterol, and triglycerides were assessed enzymatically on a Beckman Synchrony CX5 Delta Clinical System (Beckman Coulter, Fullerton, CA, USA) using commercial reagents, and low density lipoprotein (LDL) cholesterol concentration was calculated by means of the Friedewald equation for participants who had less than $400 \mathrm{mg} / \mathrm{dL}$ triglycerides [32]. Fasting blood was measured using a modified hexokinase enzymatic method. Concentration of hsCRP was determined by an immunoturbidimetric assay on a Beckman Synchron CX5 Delta Clinical System using commercial reagents. Soluble E-selectin and sICAM-1 was measured by an ELISA assay (R \& D Systems, Minneapolis, MN) which employs the quantitative sandwich enzyme immunoassay technique. Quantitative determination of immunoreactive 
angiotensin-II was performed by a double antibody radioimmunoassay (RIA) after reversed-phase sample extraction by means of phenylsilylsilica columns following the method previously reported by Emanuel et al and a commercial RIA kit [33]. In total 178 people were missing a value for 1 of the 4 biomarkers. Values were imputed by using the median value of the biomarker.

\section{Definitions}

Participants who smoked at least 1 cigarette daily for 1 year or more were defined as current smokers. Heavy alcohol consumption was defined as drinking at least 50 $\mathrm{g}$ of alcohol per day for 1 year or more. MetS was defined according to the modified Adult Treatment Panel III recommendations for Asian American [34]. Individuals were considered to have MetS if they had three or more of the following risk factors: elevated waist circumference $(\geq 90 \mathrm{~cm}$ in men, $\geq 80 \mathrm{~cm}$ in women), elevated triglycerides $(\geq 150 \mathrm{mg} / \mathrm{dL})$, reduced HDL cholesterol $(<40 \mathrm{mg} / \mathrm{dL}$ in men, $<50 \mathrm{mg} / \mathrm{dL}$ in women), elevated BP ( $\geq 130 \mathrm{mmHg}$ systolic blood pressure or $\geq 85 \mathrm{mmHg}$ diastolic blood pressure) or elevated fasting glucose $(\geq 100 \mathrm{mg} / \mathrm{dL})$. Prediabetes and diabetes cases were defined as individuals with fasting blood glucose measurements of $100-125 \mathrm{mg} / \mathrm{dL}$ and $\geq 126 \mathrm{mg} / \mathrm{dL}$, respectively.

\section{Statistical Analysis}

Participants were categorized into one of four groups based on the presence or absence of metabolic and glycemic abnormalities: 1) free of prediabetes, diabetes and MetS (reference group), 2) prediabetes or diabetes only, 3) MetS without prediabetes or diabetes, and 4) MetS plus prediabetes or diabetes. Descriptive statistics for demographic variables, components of MetS, and biomarkers of inflammation and endothelial dysfunction were calculated separately for the four groups. For continuous variables, means (standard deviations [SD]) were used to describe normally distributed variables and median (interquartile range) were calculated for variables with skewed distribution; frequencies were used to describe categorical variables. Differences between the reference group and other groups were tested using ANOVA for normally distributed continuous variables; the Wilcoxon rank-sum test for variables that did not follow a normal distribution and $\chi^{2}$ for categorical variables.

For each biomarker, participants were ranked according to concentration of the biomarker and then divided into tertiles. Mean concentrations of individual components of the MetS were calculated according to tertile of biomarker in age and gender-adjusted models and linear trends were tested. The distribution of participants was calculated by tertile of biomarker and category of metabolic or glycemic abnormality. Finally, multivariable logistic regression was used to calculate the odds ratio for prediabetes or diabetes, MetS without prediabetes or diabetes, or MetS plus prediabetes or diabetes according to tertile of plasma biomarker concentration. Consistent with other studies, we defined elevated biomarker concentration as the upper tertile of the distribution [17]. All p-values were 2-tailed and a significance level of 0.05 was used. All statistical analyses were conducted using SAS statistical software (version 9.2).

\section{Results}

The descriptive characteristics of 2,536 study participants are presented separately for the four categories of metabolic or glycemic abnormalities (table 1). Study participants had a mean (SD) age of 46.4 (12.4) years, mean BMI of $22.2(3.5) \mathrm{kg} / \mathrm{m}^{2}$, and $60 \%$ were female. In total, $3.6 \%$ of the study participants had diabetes, and $18.5 \%$ had prediabetes. Of those with prediabetes or diabetes, $61 \%$ also had the MetS and $27.4 \%$ of the entire study population had 3 or more components of the MetS. Compared to the reference group, participants with the MetS were more likely to be female, have elevated BMI, and have a family history of hypertension. In univariate analysis compared to the reference group, hsCRP was elevated in all groups, sICAM-1 was elevated among those with prediabetes or diabetes, and sE-selectin was elevated in those with MetS.

Table 2 displays the mean levels of individual components of the MetS presented by tertile of biomarker in a model adjusted for age and gender. HsCRP and sICAM1 were associated with all components of the MetS (pvalue for linear trend $\leq 0.01$ for all components). Soluble E-selectin had a linear association with blood glucose, waist circumference, and triglycerides ( $\mathrm{p}$-value $<0.01$ for linear trend). Angiotensin II was linearly associated with blood glucose, triglycerides, and blood pressure (pvalue $<0.01$ for linear trend).

Figure 1 shows the proportion of participants by tertile of biomarker and category of metabolic or glycemic abnormality. More than $40 \%$ of participants with prediabetes or diabetes only or MetS only have CRP in the upper tertile, whereas more than $60 \%$ of participants with MetS plus prediabetes or diabetes have elevated CRP. For ICAM-1, those in the top tertile comprised $44 \%$ of the individuals with prediabetes or diabetes only and more than $60 \%$ of those with MetS plus prediabetes or diabetes but only $29 \%$ of those with MetS only have elevated ICAM-1. For E-selectin, those in the top tertile comprised approximately $27 \%$ of those with prediabetes or diabetes only, $44 \%$ of those with MetS only, and 36\% of those with the combination of the two conditions. The proportion of persons with elevated Angiotensin II was $25 \%$ in those with prediabetes or diabetes only, and $35 \%$ in the other two categories. 
Table 1 Descriptive characteristics of 2,536 participants according to category of metabolic or glycemic abnormality

\begin{tabular}{|c|c|c|c|c|}
\hline & $\begin{array}{l}\text { No Prediabetes, } \\
\text { Diabetes, or MetS }\end{array}$ & $\begin{array}{l}\text { Prediabetes or } \\
\text { Diabetes only }\end{array}$ & $\begin{array}{l}\text { MetS without } \\
\text { Prediabetes or } \\
\text { Diabetes }\end{array}$ & $\begin{array}{l}\text { MetS plus } \\
\text { Prediabetes or } \\
\text { Diabetes }\end{array}$ \\
\hline No. & 1621 & 218 & 354 & 343 \\
\hline Age, y & $45.3(12.4)$ & $45.4(12.8)$ & $48.6(10.7)^{*}$ & $50.4(12.2)^{*}$ \\
\hline Female, \% & 57.2 & 50.1 & $67.0^{*}$ & $66.2^{*}$ \\
\hline Current smoker, \% & 46.8 & 42.2 & $39.3^{*}$ & $39.1^{*}$ \\
\hline Alcohol consumption, \% & 33.4 & 33.0 & 33.6 & 32.4 \\
\hline Body mass index, $\mathrm{kg} / \mathrm{m}^{2}$ & $21.4(2.9)$ & $21.0(3.2)$ & $25.0(3.3)^{*}$ & $24.3(3.8)^{*}$ \\
\hline Family history of HTN, \% & 9.9 & $18.8^{*}$ & $14.4^{*}$ & $22.5^{*}$ \\
\hline \multicolumn{5}{|c|}{ Components of the Metabolic Syndrome } \\
\hline $\mathrm{HDL}-\mathrm{C}, \mathrm{mg} / \mathrm{dL}$ & $47.6(12.3)$ & $48.5(16.2)$ & $38.3(8.0)^{*}$ & $39.8(12.2)^{*}$ \\
\hline Triglycerides, mg/dL & $86.8(61.2)$ & $79.6(40.0)$ & $189.2(180.7)^{*}$ & $172.7(177.1)^{*}$ \\
\hline Waist circumference, $\mathrm{cm}$ & $78.1(7.9)$ & $76.6(6.8)^{*}$ & $89.2(8.9)^{*}$ & $87.6(10.2)^{*}$ \\
\hline Systolic BP, mmHg & $124.7(23.2)$ & $126.1(22.3)$ & $141.5(23.4)^{*}$ & $142.9(25.1)^{*}$ \\
\hline Diastolic BP, mmHg & $81.8(12.2)$ & $82.1(11.8)$ & $92.4(11.3)^{*}$ & $90.5(12.6)^{*}$ \\
\hline Glucose, mg/dL & $81.5(10.8)$ & $112.5(14.5)^{*}$ & $84.4(10.2)^{*}$ & $119.7(34.2)^{*}$ \\
\hline \multicolumn{5}{|c|}{ Biomarkers of Inflammation and Endothelial Dysfunction } \\
\hline hsCRP, mg/L & $5.13(3.61,8.25)$ & $7.32(3.64,13.84)^{*}$ & $7.89(5.19,16.08)^{*}$ & $12.59(5.89,20.4)^{*}$ \\
\hline sICAM-1, ng/mL & $315.3(93.4)$ & $360.3(85.2)$ & $325.7(94.7)^{*}$ & $377.6(89.5)^{*}$ \\
\hline sE-selectin, ng/mL & $17.9(14.4,23.6)$ & $18.3(15.6,22.3)$ & $20.9(16.1,27.6)^{*}$ & $19.9(16.6,25.0)^{*}$ \\
\hline Angiotensin $\|, \mathrm{pg} / \mathrm{mL}$ & $49.4(39.5,71.1)$ & $46.7(40.0,60.0)$ & $50.5(41.0,73.8)$ & $49.0(40.0,86.0)$ \\
\hline
\end{tabular}

Abbreviations: BP, blood pressure; HDL-C, high density lipoprotein-cholesterol; hsCRP, high sensitivity C-reactive protein; sICAM-1, soluble intercellular adhesion molecule-1; sE-selectin, soluble E-selectin. Metabolic syndrome (MetS) was defined according to the revised ATP-III criteria defined as the presence of 3 or more of the following risk factors: waist circumference $\geq 90 \mathrm{~cm}$ for men and $\geq 80 \mathrm{~cm}$ for women, triglyceride concentration $\geq 150 \mathrm{mg} / \mathrm{dL}$, blood pressure $\geq 130 / 85$ $\mathrm{mmHg}$, fasting glucose $\geq 100 \mathrm{mg} / \mathrm{dL}$, or $\mathrm{HDL}$ cholesterol level $<40 \mathrm{mg} / \mathrm{dL}$ in men or $<50 \mathrm{mg} / \mathrm{dL}$ in women. For normally distributed variables, values are presented as means (SD) or frequencies (\%) and as median (interquartile range) for variables that did not follow a normal distribution (hsCRP, sE-selectin, and angiotensin II). P-values were computed for each category versus the reference category using ANOVA or chi-square for normally distributed variables or Wilcoxon nonparametric rank test for variables that did not follow a normal distribution, values $<0.05$ are denoted with an asterisk $(*)$.

The age and gender-adjusted odds ratios ([OR], 95\% confidence interval $[\mathrm{CI}]$ ) for prediabetes or diabetes only, MetS without prediabetes or diabetes, and MetS plus prediabetes or diabetes are presented in table 3. Compared to the reference group, elevated hsCRP was associated with increased odds for all three groups; the increased risk was similar for those with prediabetes or diabetes only $(2.27,1.69-3.06)$, and MetS only (3.00, 2.35-3.84), but was significantly higher among those with MetS plus prediabetes or diabetes (5.84, 4.53-7.53). Elevated sICAM-1 was also associated with increased odds of prediabetes or diabetes $(2.14,1.60-2.86)$ and a 4-fold increased risk of MetS plus prediabetes or diabetes $(4.15,3.24-5.31)$. Elevated sE-selectin was associated with increased odds of MetS only $(1.71,1.35$ 2.17). Elevated Angiotensin II was not significantly associated with any of the outcome groups.

When current smoking, heavy drinking, and family history of hypertension were added to the model, the results were modestly attenuated. Further addition of BMI to the model slightly attenuated most results but did not significantly change the overall results. Finally, there was no change in the overall results after excluding individuals with imputed data or excluding participants with CRP $>10 \mathrm{mg} / \mathrm{L}$.

\section{Discussion}

The primary findings of this study are that elevated levels of CRP and sICAM-1 are associated with increased odds of prediabetes or diabetes, MetS or both conditions in combination. Elevated CRP was associated with nearly 2 -fold increased odds of prediabetes or diabetes, a 2 -fold increased odds of MetS only, and nearly 5 -fold increased odds of MetS plus prediabetes or diabetes after multivariable adjustment. Elevated sICAM-1 was associated with 2-fold increased odds of having prediabetes or diabetes, and nearly 4-fold increased odds of having MetS plus prediabetes or diabetes.

In the current study, $3.6 \%$ of the study participants had diabetes which is lower than recent national estimates but $18.5 \%$ had prediabetes which is slightly higher than national estimates [6]. Using the Revised ATP III definition of the MetS, approximately $27 \%$ of the present study participants had 3 or more metabolic abnormalities, which is similar to national estimates using the same definition[4]. 
Table 2 Mean levels ( $95 \%$ confidence intervals) of individual components of the metabolic syndrome by tertile of biomarker in a model adjusted for age and gender

\begin{tabular}{|c|c|c|c|c|c|c|c|}
\hline $\begin{array}{l}\text { Tertiles of } \\
\text { Biomarker }\end{array}$ & Median & $\begin{array}{l}\text { Blood Glucose } \\
\text { (mg/dL) }\end{array}$ & $\begin{array}{c}\text { Waist } \\
\text { Circumference } \\
(\mathrm{cm})\end{array}$ & $\begin{array}{c}\text { Triglycerides } \\
\text { (mg/dL) }\end{array}$ & $\begin{array}{l}\text { HDL Cholesterol } \\
\text { (mg/dL) }\end{array}$ & $\begin{array}{c}\text { Systolic Blood } \\
\text { Pressure }(\mathrm{mmHg})\end{array}$ & $\begin{array}{l}\text { Diastolic Blood } \\
\text { Pressure (mmHg) }\end{array}$ \\
\hline \multicolumn{8}{|c|}{ hsCRP (mg/L) } \\
\hline 1 & 3.3 & $84.4(83.0,85.9)$ & $78.0(77.4,78.7)$ & $\begin{array}{c}81.2(73.8 \\
88.7)\end{array}$ & $47.7(46.9,48.6)$ & $127.5(126.0,129.0)$ & $83.2(82.4,84.0)$ \\
\hline 2 & 5.9 & $86.1(84.7,87.5)$ & $80.9(80.3,81.5)$ & $\begin{array}{c}99.7(92.4 \\
107.0)\end{array}$ & $45.7(44.9,46.6)$ & $128.4(126.9,129.9)$ & $84.2(83.4,85.0)$ \\
\hline 3 & 15.2 & $98.2(96.8,99.6)$ & $83.7(83.1,84.3)$ & $\begin{array}{l}162.9(155.7 \\
170.2)\end{array}$ & $42.4(41.5,43.2)$ & $133.6(132.2,135.2)$ & $87.1(86.3,87.9)$ \\
\hline P-value for I & ir trend & $<0.001$ & $<0.001$ & $<0.001$ & $<0.001$ & $<0.001$ & $<0.001$ \\
\hline \multicolumn{8}{|c|}{ sICAM-1 (ng/ml) } \\
\hline 1 & 234.3 & $84.2(82.8,85.7)$ & $79.8(79.2,80.5)$ & $\begin{array}{l}110.9(103.3 \\
118.6)\end{array}$ & $46.7(45.8,47.6)$ & $127.7(126.2,129.2)$ & $84.0(83.1,84.8)$ \\
\hline 2 & 329.0 & $87.8(86.4,89.3)$ & $80.7(80.6,81.3)$ & $\begin{array}{l}109.9(102.3 \\
117.6)\end{array}$ & $45.1(44.3,46.0)$ & $129.1(127.5,130.5)$ & $84.5(83.7,85.3)$ \\
\hline 3 & 421.4 & $96.9(95.4,98.3)$ & $82.2(81.5,82.9)$ & $\begin{array}{l}125.1(117.5 \\
132.7)\end{array}$ & $43.9(43.0,44.7)$ & $133.0(131.5,134.5)$ & $86.1(85.3,86.9)$ \\
\hline P-value for & ar trend & $<0.001$ & $<0.001$ & 0.01 & $<0.001$ & $<0.001$ & 0.001 \\
\hline \multicolumn{8}{|c|}{ sE-selectin (ng/mL) } \\
\hline 1 & 13.6 & $86.2(84.8,87.7)$ & $79.0(78.4,79.7)$ & $\begin{array}{l}104.8(97.1 \\
112.5)\end{array}$ & $46.0(45.1,46.9)$ & $128.7(127.2,130.2)$ & $83.8(82.9,84.6)$ \\
\hline 2 & 18.3 & $92.0(90.5,93.4)$ & $81.4(80.8,82.0)$ & $\begin{array}{l}111.2(103.6 \\
118.9)\end{array}$ & $45.0(44.2,45.9)$ & $132.2(130.7,133.7)$ & $85.9(85.1,86.7)$ \\
\hline 3 & 27.9 & $90.8(89.4,92.3)$ & $82.3(81.7,82.9)$ & $\begin{array}{l}129.6(122.1 \\
137.2)\end{array}$ & $44.7(43.8,45.5)$ & $128.8(127.3,130.3)$ & $84.9(84.1,85.7)$ \\
\hline P-value for & ar trend & $<0.001$ & $<0.001$ & $<0.001$ & 0.04 & 0.49 & 0.20 \\
\hline \multicolumn{8}{|c|}{ Angiotensin II (pg/mL) } \\
\hline 1 & 36.0 & $90.8(89.3,92.3)$ & $80.8(80.1,81.4)$ & $\begin{array}{l}104.1(96.4 \\
111.8)\end{array}$ & $46.1(45.2,46.9)$ & $127.1(125.6,128.6)$ & $83.4(82.6,84.2)$ \\
\hline 2 & 48.8 & $90.4(89.0,91.9)$ & $81.0(80.3,81.6)$ & $\begin{array}{l}113.2(105.5 \\
120.8)\end{array}$ & $43.8(43.0,44.7)$ & $129.7(128.2,131.2)$ & $84.8(84.0,85.7)$ \\
\hline 3 & 89.5 & $87.9(86.4,89.3)$ & $81.1(80.4,81.7)$ & $\begin{array}{l}128.3(120.8 \\
135.9)\end{array}$ & $45.8(44.9,46.6)$ & $132.9(131.4,134.3)$ & $86.3(85.5,87.1)$ \\
\hline \multicolumn{2}{|c|}{ P-value for linear trend } & 0.003 & 0.56 & $<0.001$ & 0.49 & $<0.001$ & $<0.001$ \\
\hline
\end{tabular}

Abbreviations: hsCRP, high sensitivity C-reactive protein; sICAM-1, soluble Intercellular adhesion molecule-1; sE-selectin, soluble E-selectin.

Our findings are consistent with other studies that have reported a significant association between elevated CRP and prediabetes, diabetes $[17,21,26]$ or MetS $[21,28,30,35]$. Our finding that sICAM-1 was associated with increased odds for prediabetes and diabetes is consistent with the association reported by the Women's Health Initiative Observational Study (OR for the highest verses lowest quartile of ICAM-1 values: $2.34,95 \%$ CI 1.75, 3.13) but the odds were higher in the Nurse's Health Study (OR for the highest verses lowest quintile of ICAM-1 values: $3.56,95 \%$ CI $2.28,5.58$ ), possibly due to analysis by quintiles rather than tertiles of biomarker concentration $[18,19]$.

Levels of sE-selectin have been shown to be independently associated with diabetes and MetS [18-20]. Ingelsson et al. reported a $26 \%$ increased odds of MetS (OR 1.26, 95\% CI 1.06-1.50) for each standard deviation increase in $\log$ E-selectin [20]. Unlike our study, the Women's Health Initiative Observational Study found Eselectin to be a predictor of diabetes; however, the U.S. women had higher median E-selectin levels, higher mean BMI and higher mean waist circumference than the women included in our study [19]. Angiotensin II has been thought to contribute to altering glucose and lipid metabolism by inhibiting formation of smaller, less insulin-resistant adipocytes. Although a positive linear association was identified between Angiotensin II and individual components of MetS, elevated angiotensin II levels were not associated with increased risk of MetS, prediabetes or diabetes only, or MetS plus prediabetes or diabetes. To our knowledge, no other studies have examined this association.

The mechanisms responsible for increased cardiovascular morbidity and mortality in individuals with 


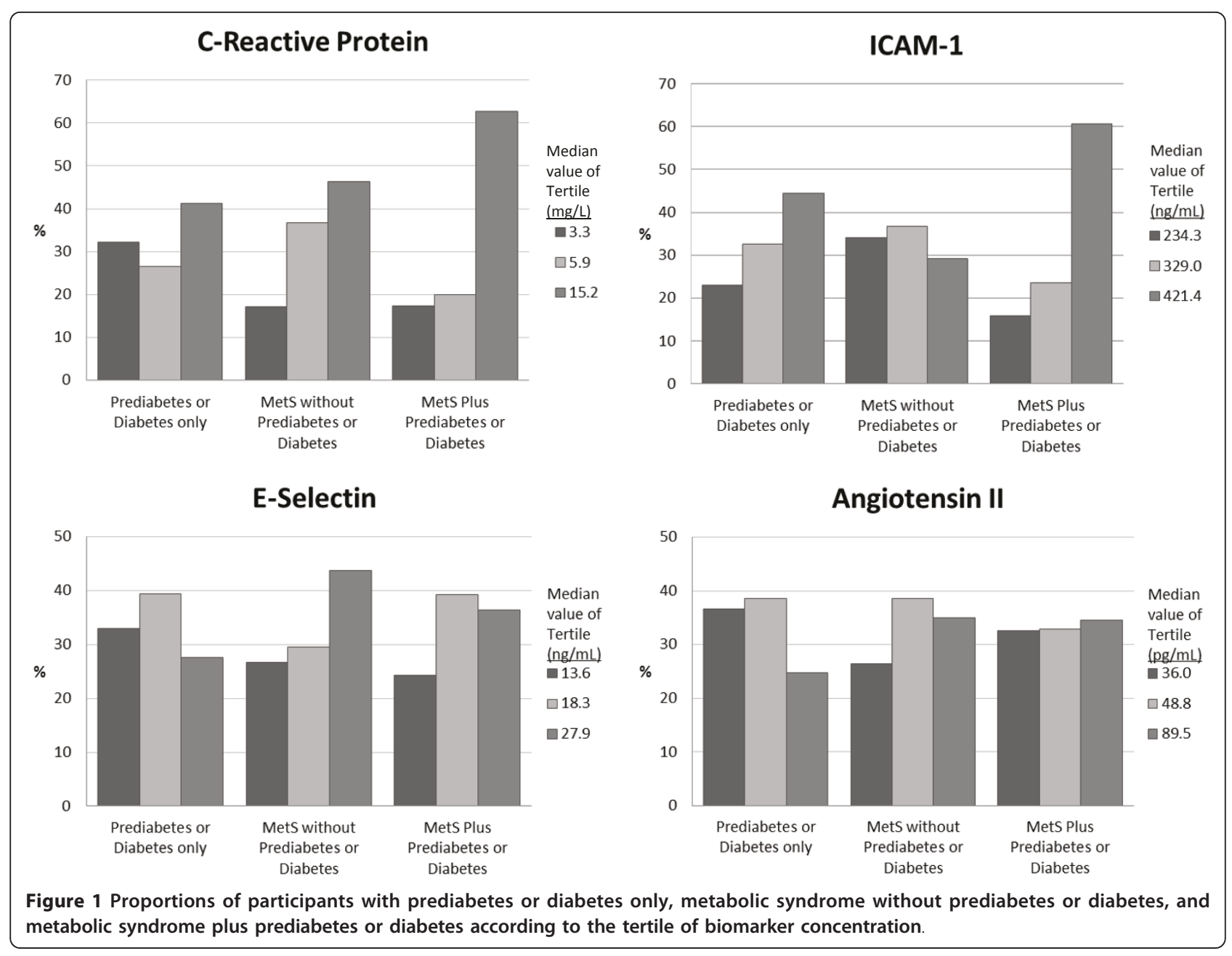

Table 3 Odds ratios for metabolic or glycemic abnormality associated with elevated biomarkers of inflammation and endothelial dysfunction

\begin{tabular}{|c|c|c|c|c|}
\hline & $\begin{array}{l}\text { No Prediabetes, } \\
\text { Diabetes, or MetS }\end{array}$ & $\begin{array}{l}\text { Prediabetes or } \\
\text { Diabetes only }\end{array}$ & $\begin{array}{c}\text { MetS without } \\
\text { Prediabetes or } \\
\text { Diabetes }\end{array}$ & $\begin{array}{c}\text { MetS plus } \\
\text { Prediabetes or } \\
\text { Diabetes }\end{array}$ \\
\hline \multicolumn{5}{|l|}{ hsCRP (mg/L) } \\
\hline Age, gender & 1.00 & $2.27(1.69,3.06)$ & $3.00(2.35,3.84)$ & $5.84(4.53,7.53)$ \\
\hline Multivariable & 1.00 & $2.22(1.65,3.00)$ & $2.97(2.33,3.80)$ & $5.70(4.41,7.33)$ \\
\hline Multivariable + BMl & 1.00 & $2.29(1.69,3.10)$ & $2.38(1.82,3.11)$ & $4.82(3.69,6.31)$ \\
\hline \multicolumn{5}{|l|}{ sICAM-1 (ng/ml) } \\
\hline Age, gender & 1.00 & $2.14(1.60,2.86)$ & $1.13(0.88,1.46)$ & $4.15(3.24,5.31)$ \\
\hline Multivariable & 1.00 & $2.06(1.54,2.76)$ & $1.10(0.85,1.43)$ & $3.98(3.10,5.12)$ \\
\hline Multivariable + BMI & 1.00 & $2.11(1.58,2.83)$ & $0.91(0.69,1.21)$ & $3.43(2.64,4.47)$ \\
\hline \multicolumn{5}{|l|}{ sE-selectin (ng/mL) } \\
\hline Age, gender & 1.00 & $0.82(0.60,1.12)$ & $1.71(1.35,2.17)$ & $1.27(0.99,1.62)$ \\
\hline Multivariable & 1.00 & $0.82(0.60,1.13)$ & $1.71(1.35,2.17)$ & $1.28(1.00,1.64)$ \\
\hline Multivariable + BMI & 1.00 & $0.85(0.62,1.17)$ & $1.38(1.06,1.79)$ & $1.06(0.81,1.38)$ \\
\hline \multicolumn{5}{|c|}{ Angiotensin II (pg/mL) } \\
\hline Age, gender & 1.00 & $0.63(0.45,0.87)$ & $1.09(0.85,1.39)$ & $1.05(0.82,1.35)$ \\
\hline Multivariable & 1.00 & $0.63(0.45,0.87)$ & $1.06(0.83,1.36)$ & $1.00(0.78,1.29)$ \\
\hline Multivariable + BMI & 1.00 & $0.62(0.45,0.86)$ & $1.12(0.86,1.46)$ & $1.05(0.80,1.37)$ \\
\hline
\end{tabular}

Abbreviations: MetS, Metabolic Syndrome; hsCRP, high sensitivity C-reactive protein; sICAM-1, soluble Intercellular adhesion molecule-1; sE-selectin, soluble Eselectin; BG, blood glucose. The multivariable models are adjusted for age, gender, smoking, drinking and family history of hypertension. 
diabetes or MetS, are not fully explained by traditional risk factors and may be partially explained by inflammation and endothelial dysfunction. Visceral adiposity is associated with increased production of proinflammatory cytokines and hepatic CRP. ICAM-1 is also associated with visceral adiposity and may be upregulated by the increased production of proinflammatory cytokines [36]. Inflammation may promote development of diabetes by triggering beta cell dysfunction, apoptosis and impaired insulin signaling or development of hypertension by influencing platelet adhesion and aggregation, production of oxidants and induction of renal vasoconstriction [37].

The median level of CRP in our study participants was higher than reported in other studies with Asian populations $[26,28,30,35]$ and may be due to analytic or preanalytic sources of variability such as a lack of standardized reference material for CRP measurement, inclusion of participants with CRP $>10 \mathrm{mg} / \mathrm{L}$, diet high in fats and salts or subclinical or untreated disease.

This study has several strengths including homogeneity of lifestyle, dietary habits and ethnic background of study participants. Study personnel were well trained and data was collected with rigid quality control. Due to the cross sectional nature of this study, it is not possible to establish temporality or determine if elevated biomarkers lead to development of the prediabetes, diabetes or MetS or if development of the individual components of the MetS lead to inflammation and endothelial dysfunction. Additional limitation includes the fact that prediabetes and diabetes were defined based on the fasting glucose along, which will underestimate the prevalence [6].

\section{Conclusions}

In conclusion, the results from our study, indicated a strong association between elevated biomarkers of inflammation and endothelial dysfunction with increased odds of prediabetes, diabetes and the MetS among adults in Inner Mongolia, China. Strategies to reduce inflammation may be important therapeutic targets for people at risk of developing diabetes or MetS.

\section{Acknowledgements}

We are deeply appreciative of the participants in the study, and thank Kezuohouqi Banner Center for Disease Prevention and Control, and Naiman Banner Center for Disease Prevention and Control for their support and assistance. This study was supported by National Natural Science Foundation of China (Grant No. 30471484) and partially supported by Tulane University School of Public Health and Tropical Medicine.

\section{Author details}

${ }^{1}$ Department of Epidemiology, Tulane University School of Public Health and Tropical Medicine, New Orleans, Louisiana, USA. ${ }^{2}$ Department of Epidemiology, School of Radiation Medicine and Public Health, Medical College of Soochow University, Suzhou, Jiangsu, PR China. ${ }^{3}$ Department of
Medicine, Tulane University School of Medicine, New Orleans, Louisiana, USA. ${ }^{4}$ Tongliao Center for Disease Prevention and Control, Tongliao, Inner Mongolia, PR China.

\section{Authors' contributions}

AMT analyzed the data and drafted the manuscript. YZ participated in the design and coordination of the study and helped to revise the manuscript. WT, TX, and LZ helped with acquisition of data and helped revised the manuscript. JC participated in the study design and coordination and helped to revise the manuscript. TNK helped with interpretation of data and revised the manuscript. CSC analyzed the data and revised the manuscript. $\angle A B$ helped with the interpretation of data and to revised the manuscript. $\mathrm{JH}$ conceived of the study, participated in its design and coordination and helped to draft the manuscript. All authors read and approved the final manuscript.

\section{Competing interests}

The authors declare that they have no competing interests.

Received: 14 September 2010 Accepted: 11 October 2011 Published: 11 October 2011

\section{References}

1. Ilanne-Parikka P, Eriksson JG, Lindström J, Hämäläinen $H$, KeinänenKiukaanniemi S, Laakso M, Louheranta A, Mannelin M, Rastas M, Salminen V, Aunola S, Sundvall J, Valle T, Lahtela J, Uusitupa M, Tuomilehto J: Prevalence of the Metabolic Syndrome and Its Components. Diabetes Care 2004, 27(9):2135-2140.

2. Ford ES: The metabolic syndrome and mortality from cardiovascular disease and all-causes: findings from the National Health and Nutrition Examination Survey II Mortality Study. Atherosclerosis 2004, 173(2):307-312.

3. Reynolds K, He J: Epidemiology of the metabolic syndrome. Am J Med Sci 2005, 330(6):273-279.

4. Yang W, Reynolds K, Gu D, Chen J, He J: A Comparison of Two Proposed Definitions for Metabolic Syndrome in the Chinese Adult Population. Am J Med Sci 2007, 334(3):184-189.

5. Tong PC, Kong AP, So W, Yang X, Ho C, Ma RC, Ozaki R, Chow C, Lam CW, Chan JCN, Cockram CS: The Usefulness of the International Diabetes Federation and the National Cholesterol Education Program's Adult Treatment Panel III Definitions of the Metabolic Syndrome in Predicting Coronary Heart Disease in Subjects With Type 2 Diabetes. Diabetes Care 2007, 30(5):1206-1211.

6. Yang W, Lu J, Weng J, Jia W, Ji L, Xiao J, Shan Z, Liu J, Tian H, Ji Q, Zhu D, Ge J, Lin L, Chen L, Guo X, Zhao Z, Li Q, Zhou Z, Shan G, He J, The China National Diabetes and Metabolic Disorders Study Group: Prevalence of Diabetes among Men and Women in China. N Engl J Med 2010, 362(12):1090-1101.

7. Grundy SM, Brewer HB, Cleeman JI, Smith SC, Lenfant C, For the Conference Participants: Definition of Metabolic Syndrome. Circulation 2004, 109(3):433-438.

8. Mancia G, Bombelli M, Corrao G, Facchetti R, Madotto F, Giannattasio C, Trevano FQ, Grassi G, Zanchetti A, Sega R: Metabolic Syndrome in the Pressioni Arteriose Monitorate E Loro Associazioni (PAMELA) Study: Daily Life Blood Pressure, Cardiac Damage, and Prognosis. Hypertension 2007, 49(1):40-47

9. Galassi A, Reynolds K, He J: Metabolic Syndrome and Risk of Cardiovascular Disease: A Meta-Analysis. Am J Med 2006, 119(10):812-819.

10. Dekker JM, Girman C, Rhodes T, Nijpels G, Stehouwer CDA, Bouter LM, Heine RJ: Metabolic Syndrome and 10-Year Cardiovascular Disease Risk in the Hoorn Study. Circulation 2005, 112(5):666-673.

11. Zhang WW, Liu CY, Wang YJ, Xu ZQ, Chen Y, Zhou HD: Metabolic syndrome increases the risk of stroke: a 5-year follow-up study in a Chinese population. J Neurol 2009, 256(9):1493-1499.

12. Chen J, Muntner $\mathrm{P}$, Hamm LL, Jones DW, Batuman V, Fonseca V, Whelton PK, He J: The Metabolic Syndrome and Chronic Kidney Disease in U.S. Adults. Annals of Internal Medicine 2004, 140(3):167-174.

13. Vaidya D, Mathias RA, Kral BG, Yanek LR, Becker LC, Becker DM: Independent Metabolic Syndrome Variants Predict New Onset Coronary Artery Disease. Diabetes Care 2010.

14. Zhang Y, Hong J, Gu W, Gui M, Chen Y, Zhang Y, Chi Z, Wang W, Li X, Ning G: Impact of the metabolic syndrome and its individual 
components on risk and severity of coronary heart disease. Endocrine 2009, 36(2):233-238.

15. Church TS, Thompson AM, Katzmarzyk PT, Sui X, Johannsen N, Earnest CP, Blair SN: Metabolic Syndrome and Diabetes, Alone and in Combination, as Predictors of Cardiovascular Disease Mortality Among Men. Diabetes Care 2009, 32(7):1289-1294.

16. de Jager J, Dekker JM, Kooy A, Kostense PJ, Nijpels G, Heine RJ, Bouter LM Stehouwer CD: Endothelial dysfunction and low-grade inflammation explain much of the excess cardiovascular mortality in individuals with type 2 diabetes: the Hoorn Study. Arterioscler Thromb Vasc Biol 2006, 26(5):1086-1093.

17. Lee CC, Adler Al, Sandhu MS, Sharp SJ, Forouhi NG, Erqou S, Luben R, Bingham S, Khaw KT, Wareham NJ: Association of C-reactive protein with type 2 diabetes: prospective analysis and meta-analysis. Diabetologia 2009, 52(6):1040-1047.

18. Meigs JB, Hu FB, Rifai N, Manson JE: Biomarkers of Endothelial Dysfunction and Risk of Type 2 Diabetes Mellitus. JAMA 2004, 291(16):1978-1986.

19. Song Y, Manson JE, Tinker L, Rifai N, Cook NR, Hu FB, Hotamisligil GS, Ridker PM, Rodriguez BL, Margolis KL, Oberman A, Liu S: Circulating Levels of Endothelial Adhesion Molecules and Risk of Diabetes in an Ethnically Diverse Cohort of Women. Diabetes 2007, 56(7):1898-1904.

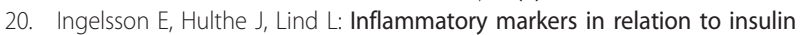
resistance and the metabolic syndrome. Eur J Clin Invest 2008, 38(7):502-509.

21. Laaksonen DE, Niskanen L, Nyyssönen K, Punnonen K, Tuomainen TP, Valkonen VP, Salonen R, Salonen JT: C-reactive protein and the development of the metabolic syndrome and diabetes in middle-aged men. Diabetologia 2004, 47(8):1403-1410.

22. Pischon T, Hu FB, Rexrode KM, Girman CJ, Manson JE, Rimm EB: Inflammation, the metabolic syndrome, and risk of coronary heart disease in women and men. Atherosclerosis 2008, 197(1):392-399.

23. Jacobs M, van Greevenbroek MMJ, van der Kallen CJH, Ferreira I, Blaak E, Feskens EJM, Jansen EHJM, Schalkwijk C, Stehouwer CDA: The association between the metabolic syndrome and peripheral, but not coronary, artery disease is partly mediated by endothelial dysfunction: the CODAM study. Eur J Clin Invest 2011, 41(2):167-175.

24. Hu FB, Meigs JB, Li TY, Rifai N, Manson JE: Inflammatory markers and risk of developing type 2 diabetes in women. Diabetes 2004, 53(3):693-700.

25. Pradhan AD, Manson JE, Rifai N, Buring JE, Ridker PM: C-reactive protein, interleukin 6, and risk of developing type 2 diabetes mellitus. JAMA 2001, 286(3):327-334.

26. Ye X, Franco OH, Yu Z, Li H, Hu FB, Liu H, Wang X, Tang H, Liu Y, Chen Y, $L$ in $X$ : Associations of inflammatory factors with glycaemic status among middle-aged and older Chinese people. Clin Endocrinol 2009, 70(6):854-862.

27. Lin J, Zhang M, Song F, Qin J, Wang R, Yao P, Ying C, Hu FB, Liu L: Association between C-reactive protein and pre-diabetic status in a Chinese Han clinical population. Diabetes Metab Res Rev 2009, 25(3):219-223.

28. Hsu LA, Ko YL, Wu S, Teng MS, Chou HH, Chang CJ, Chang PY: Association of soluble intercellular adhesion molecule- 1 with insulin resistance and metabolic syndrome in Taiwanese. Metabolism 2009, 58(7):983-988.

29. Wen J, Liang Y, Wang F, Sun L, Guo Y, Duan X, Liu X, Tao Q, Wong TY, Lu X, Wang N: Association of C-reactive protein and metabolic syndrome in a rural Chinese population. Clin Biochem 2009, 42(10-11):976-983.

30. Ye X, Yu Z, Li H, Franco OH, Liu Y, Lin X: Distributions of C-reactive protein and its association with metabolic syndrome in middle-aged and older Chinese people. J Am Coll Cardiol 2007, 49(17):1798-1805.

31. Li H, Xu T, Tong W, Liu Y, Zhao L, Zhang Y: Comparison of Cardiovascular Risk Factors Between Prehypertension and Hypertension in a Mongolian Population, Inner Mongolia, China. Circ J 2008, 72(10):1666-1673.

32. Friedewald WT, Levy RI, Fredrickson DS: Estimation of the Concentration of Low-Density Lipoprotein Cholesterol in Plasma, Without Use of the Preparative Ultracentrifuge. Clin Chem 1972, 18(6):499-502.

33. Emanuel RL, Cain JP, Williams GH: Double antibody radioimmunoassay of renin activity and angiotensin II in human peripheral plasma. J Lab Clin Med 1973, 81:632-640.

34. Grundy SM, Cleeman J, Daniels SR, Donato KA, Eckel RH, Franklin BA, Gordon DJ, Krauss RM, Savage PJ, Smith SC, Spertus JA, Costa F: Diagnosis and Management of the Metabolic Syndrome. Circulation 2005, 112(17):2735-2752

35. Lao XQ, Thomas GN, Jiang CQ, Zhang WS, Yin P, Adab P, Lam TH, Cheng KK: c-Reactive protein and the metabolic syndrome in older Chinese: Guangzhou Biobank Cohort Study. Atherosclerosis 2007, 194(2):483-489.

36. Leinonen E, Hurt-Camejo E, Wiklund O, Hultén LM, Hiukka A, Taskinen M: Insulin resistance and adiposity correlate with acute-phase reaction and soluble cell adhesion molecules in type 2 diabetes. Atherosclerosis 2003, 166(2):387-394.

37. Goldberg RB: Cytokine and Cytokine-Like Inflammation Markers, Endothelial Dysfunction, and Imbalanced Coagulation in Development of Diabetes and Its Complications. J Clin Endocrinol Metab 2009, 94(9):3171-3182

\section{Pre-publication history}

The pre-publication history for this paper can be accessed here: http://www.biomedcentral.com/1472-6823/11/16/prepub

doi:10.1186/1472-6823-11-16

Cite this article as: Thompson et al: Association of inflammation and endothelial dysfunction with metabolic syndrome, prediabetes and diabetes in adults from Inner Mongolia, China. BMC Endocrine Disorders 2011 11:16.

\section{Submit your next manuscript to BioMed Central and take full advantage of:}

- Convenient online submission

- Thorough peer review

- No space constraints or color figure charges

- Immediate publication on acceptance

- Inclusion in PubMed, CAS, Scopus and Google Scholar

- Research which is freely available for redistribution

Submit your manuscript at www.biomedcentral.com/submit
C) Biomed Central 